\title{
Abstract
}

Juntendo Medical Journal

2020. $66(2), 127-128$

\section{A Look at the Community-Quota System for Rural Medicine and Student Attitudes at Juntendo University}

\author{
CHIKAKO NAOE* \\ *Faculty of Medicine, Juntendo University, Tokyo, Japan
}

In Japan, until 2007 the number of medical school enrollment had decreased from 8,280 to 7,625 due to the prediction of future surplus of medical doctors. However, the decision was reversed and now 9,419 students enter medical school. In order to improve the geographical disparities, a special quota was allocated for applicants who are willing to stay in the prefecture where the school is located; it is called community-quota (chiiki-waku). Chiiki-Waku was started in 2008 and 2,293 students of the quota graduated by $2018^{1}$.

On the other hand, according to a report from Nagasaki ${ }^{2)}, 54 \%$ of the community-quota students had returned their scholarship and withdrawn (34.6\% was still at school). While $30 \%$ of the students enrolled as quota expressed their willingness of engaging community medicine but less than $10 \%$ of the graduates chose the primary care as their specialty ${ }^{3)}$. Among 67 colleges which have instituted Chiiki-Waku system, 30 colleges provide lectures about community medicine and 26 send students to community rotation ${ }^{4)}$.

To explore what affect medical students' willingness to practice in underserved areas, I conducted a crosssectional survey involving Chiiki-Waku students from second to final year at Juntendo University. The questionnaire asked students their future career preference including a specialty, area of practice, and types of medical facilities. I analyzed the association with time spent in rural clinics as a student. Response rate was $92.4 \%$ (61 of the 66 Chiiki-Waku students). Analysis of covariance was used to test for the differences. The potential confounders (i.e. gender, year in medical school and the types of Chiiki-Waku) were adjusted in the analyses.

This study demonstrated that the Chiiki-Waku students (years 2 to 6) who participated in electives at rural practice expressed more interest in working in a rural area and tended to choose specialties in primary care, such as pediatrics $(\mathrm{p}<0.05)$. Moreover, students who experienced rural practice had positive perceptions toward community medicine compared with their retrospective feelings upon first entering medical school.

Further follow-up study is needed to elucidate the causal effects of clinical experience in rural areas on their perception of future career.

Key words: medical education, Chiiki-Waku (community-quota system), carrier preference, rural medicine, cross-sectional study

\section{Acknowledgements}

This study was supported by Prof. Yuko Takeda (Faculty of Medicine, Juntendo University) and Dr.
Manabu Saito (Rural Generalist Program Japan, GENEPRO, Founder / Program director). The author appreciates their support for the editing of this manuscript.

\section{Chikako Naoe}

Faculty of Medicine, Juntendo University

2-1-1 Hongo, Bunkyo-ku, Tokyo 113-8421, Japan

TEL: +81-3-3813-3111 E-mail: med2114081@stud.juntendo.ac.jp

Research of the 2nd Alumni Scientific Award for Medical Student, Juntendo University School of Medicine

〔Received Aug. 19, 2019〕〔Accepted Sep. 26, 2019〕

Copyright (C) 2020 The Juntendo Medical Society. This is an open access article distributed under the terms of Creative Commons Attribution License (CC BY), which permits unrestricted use, distribution, and reproduction in any medium, provided the original source is properly credited. doi: 10.14789/jmj.2020.66.JMJ19-A02 


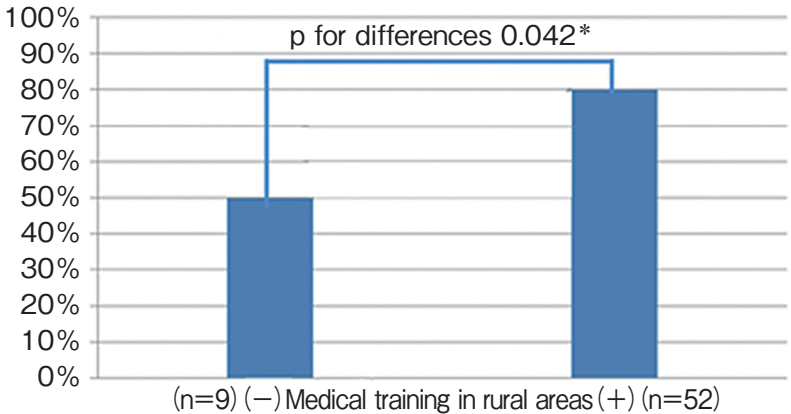

Figure-1 The proportion of students preferred to work in rural area $(n=61)$

\section{Reference}

1) Ministry of Education, Medical Education Division, survey, 2017. http://www.mhlw.go.jp/file/05-Shingikai-1080100 0-Iseikyoku-Soumuka/0000199249.pdf (Last Accessed on 2019-11-18)

2) Kaku A, Matsushita A: A web-based cross-sectional survey of municipal government scholarships associated with selective medical school for medically underserved areas. Journal of General and Family Medicine, 2015; 38: 60-66.

3) Takayashiki A: Motives, difficulties and career goals of

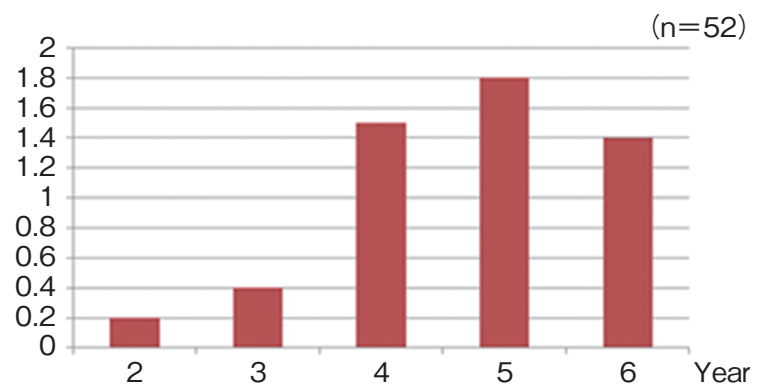

Figure-2 Means of changes in scores* of willingness to work at rural areas among students with rural clinic experience

* Differnces between retrospective scores upon entering medical school and at present.

medical students who entered medical school under the special admission system for medically underserved areas in Japan. KAKENHI-Report in Japanese, 2014. https://tsukuba.repo.nii.ac.jp/index.php?action = pages_ view_main\&active_action $=$ repository_action_common download\&item_id $=30180 \&$ item_no $=1$ \&attribute_id = 17\&file_no $=1 \&$ page_id $=13 \&$ block_id $=83$ (Last Accessed on 2019-11-18)

4) AJMC (Association of Japanese Medical Colleges) survey, 2017. 平成 29 年度地域枠入学制度と 地域医療支 援センターの実情に関する調查報告. https://www.ajmc. jp/pdf/chiikiwaku-29. pdf (Last Accessed on 2019-1118) (in Japanese) 